\title{
EVALUASI SISWA PADA PROSES KEGIATAN BELAJAR MENGAJAR DALAM PENERAPAN KURIKULUM 2013 DI SMK NEGERI JAKARTA
}

\author{
lip Apipah,,$^{1 *}$, R. Eka Murtinugraha, ${ }^{2}$, Arris Maulana. ${ }^{3}$ \\ 1 Pendidikan Teknik Bangunan, FT UNJ, Jakarta, Indonesia \\ 2 Pendidikan Teknik Bangunan, FT UNJ, Jakarta, Indonesia. \\ 3 Pendidikan Teknik Bangunan, FT UNJ, Jakarta, Indonesia \\ ${ }^{*}$ Corresponding author: iifafifah100@gmail.com
}

\begin{abstract}
This research shows with regard to the evaluation of learning implementation in the vocational school of 1, 26 and 35 of Jakarta particularly the skills of structure image engineering of student grade $X$ in the subject of image technique, which is observed from planning, implementing and lesson result view.

It is descriptive evaluative research by using quantitative approach. The model of study choosen is stake evaluation as the researcher has a tendency to understand learning activity which is seen from planning, implementing and lesson result view. The study is carried out in state vocational school of 1, 26, and 35 Jakarta with 118 respondents of student grade $X$. 36 questionnaires are used for the method of gathering data which had been tested for knowing the valitidy and reliability instrument of the questionnaire in advance. Percentage descriptive analisis is used for the technique of analysis.

The aforementioned evidence reveals that the implementation of learning in state vocational school of 1, 26 and 35 Jakarta particularly the skills of structure image engineering of student grade $X$ in the subject of image technique can be seen: The evaluation percentage to lesson plan which include planning of maintaining learning activity, planning of managing study, planning of class management, and planning of student achievements show very good resuly at the average of $80,30 \%$, percentage of learning evaluation includes space, time, learning facility, knowing understanding learning material, using learning source or resource, managing class interaction, assignment implementation, and giving feedback reveals best resuly at the average of 79,83\% and learning evaluation indicator include undertaking grading over the course of learning process, grading to the student behavior on learning, and student result which is grouped very good with the average of $80,93 \%$.
\end{abstract}

Keywords: Evaluation, planning, Implementing, result/evaluation 


\section{PENDAHULUAN}

Pendidikan nasional berfungsi mengembangkan dan membentuk watak serta peradaban bangsa yang bermartabat dalam rangka mencerdaskan kehidupan bangsa. Untuk itu, pendidikan nasional bertujuan untuk mengembangkan potensi peserta didik agar menjadi manusia yang beriman dan bertakwa kepada Tuhan Yang Maha Esa, berakhlak mulia, sehat, berilmu, cakap, kreatif, mandiri dan menjadi warga Negara yang demokratis serta bertanggung jawab (Undang-undang No. 20 Tahun 2003).

Perubahan dalam ilmu pengetahuan dan teknologi semakin maju, yang tidak mengikuti perkembangan sesuai zaman akan berakibat pada tetap tertinggalnya suatu bangsa. Oleh karena itu, sumber daya manusia yang berkualitas merupakan wujud dari tanggung jawab pendidikan terutama dalam mempersiapkan peserta didik menjadi subjek yang semakin berperan dalam menampilkan keunggulan dirinya yang tangguh, kreatif, mandiri, dan profesional dalam bidangnya masing-masing.

Berkenaan dengan hal tersebut maka konsep pendidikan nasional dewasa ini, harus mengacu pada pendidikan nasional yang memiliki keunggulan kompetitif dan komperatif sesuai standar mutu nasional dan internasional, yang dapat merespon secara produktif sebagai perkembangan informasi ilmu pengetahuan, teknologi dan arus globalisasi (E. Mulyasa, 2004: 4).

Menghadapi hal tersebut, perlu dilakukan penataan terhadap sistem pendidikan yang menyeluruh, terutama dalam rangka peningkatan mutu pendidikan yang relevansinya dengan kebutuhan masyarakat dan dunia kerja. Pendidikan diyakini sebagai sarana untuk mengubah taraf hidup manusia kearah yang lebih baik, oleh karena itu kegiatan belajar mengajar harus dapat membekali peserta didik dengan kecakapan hidup yang sesuai dengan lingkungan dan kebutuhan peserta didik. Untuk kepentingan tersebut diperlukan perubahan yang cukup mendasar dalam sistem pendidikan nasional antara lain perubahan kurikulum.

Berkaitan dengan perubahan kurikulum, berbagai pihak menganalisa dan melihat perlunya diterapkan kurikulum 2013 yang dapat membekali peserta didik dengan berbagai kemampuan yang sesuai dengan tuntutan zaman dan tuntutan reformasi, guna menjawab tantangan arus globalisasi, berkontribusi pada pembangunan masyarakat dan kesejahteraan sosial, untuk adaftif terhadap berbagai perubahan. Kurikulum 2013 ini diharapkan mampu memecahkan berbagai persoalan bangsa khusunya dalam bidang pendidikan dengan mempersiapkan siswa melalui perencanaan, pelaksanaan, dan evalusi terhadap sistem pendidikan secara efektif, efsien, dan berhasil guna.

Menurut Undang-undang Nomor 20 Tahun 2003 tentang Sistem Pendidikan Nasional menyebutkan bahwa kurikulum adalah seperangkat rencana dan pengaturan mengenai tujuan, isi, dan bahan pelajaran serta cara yang digunakan sebagai pedoman penyelenggaraan kegiatan pembelajaran untuk mencapai tujuan pendidikan tertentu.

Menurut Muzamiroh (2013: 16) Berdasarkan pengertian tersebut, ada empat dimensi kurikulum, yaitu berupa gagasan, suatu rencana tertulis, suatu kegiatan dan hasil. Kurikulum dianggap sebagai pengalaman atau seluruh aktivitas peserta didik, maka untuk memahami kurikulum sekolah tidak cukup hanya dengan melihat dokumen kurikulum sebagai suatu program 
tertulis, juga bagaimana proses pembelajaran yang dilakukan oleh peserta didik baik di Sekolah maupun di luar Sekolah. Hal ini harus dipahami sebab kaitannya sangat erat dengan evaluasi keberhasilan pelaksanaan suatu kurikulum yaitu bahwa pencapaian target pelaksanaan kurikulum tidak hanya diukur dari kemampuan peserta didik menguasai seluruh isi atau materi pelajaran seperti yang tergambar dari hasil tes sebagai produk belajar, tetapi juga harus dilihat dari proses atau kegiatan peserta didik sebagai pengalaman belajar.

Jadi kurikulum itu bukan sekedar ide yang tertuang dalam kertas menjadi sebuah dokumen, tapi dikatakan kurikulum jika dokumen tadi menjadi sebuah aktifitas yang mampu menghasilkan sesuatu. Implementasinya di sekolah, kurikulum harus tersusun secara sistematik agar proses yang dilalui peserta didik itu mengacu kepada tujuan pendidikan. Kurikulum 2013 yang diberlakukan mulai tahun ajaran 2013/2014 memenuhi keempat dimensi tersebut.

Penyelenggaraan kurikulum 2013 di Sekolah Menengah kejuruan (SMK) Kompetensi Keahlian Teknik Gambar Bangunan merupakan bagian dari proses pendidikan formal untuk meningkatkan kualitas dan produktifitas sumber daya manusia. Sebagai salah satu pendidikan formal yang menyiapkan tenaga kerja, SMK Negeri dituntut mampu menghasilkan lulusan sebagaimana yang diharapkan oleh dunia kerja. Dunia kerja membutuhkan tenaga kerja yang memiliki kompetensi sesuai dengan bidang pekerjaannya, memiliki daya adaptasi dan daya saing yang tinggi. Atas dasar itu SMK Negeri perlu terus menerus meningkatkan mutu kinerjanya sehingga harapan masyarakat terutama dunia kerja tersebut dapat terpenuhi. Pengembangan pembelajaran dan keterampilan di SMK Negeri Kompotensi Keahlian Teknik Gambar Bangunan dapat dilakukan dengan pengembangan kurikulumnya.

Mengingat kondisi SMK bervariasi, baik dilihat dari jenis Kompetensi keahlian atau jurusan, fasilitas dan sumber daya manusianya, maka perlu dilakukan evaluasi untuk mengetahui proses penerapan kurikulum 2013 dalam perencanaan pembelajaran, pelaksanaan pembelajaran dan evaluasi/hasil pembelajaran di SMK Negeri Jakarta pada Kompetensi Keahlian Teknik Gambar Bangunan. Evaluasi ini mencakup evaluasi perencanaan pembelajaran indikatornya berupa merencanakan pengelolaan kegiatan pembelajaran, merencanakan pengorganisasian bahan pembelajaran, merencanakan pengelolaan kelas, dan merencanakan prestasi belajar siswa. Evaluasi pelaksanaan pembelajaran indikatornya berupa, mengelola ruang, waktu, dan fasilitas pembelajaran, menggunakan metode pembelajaran, mengetahui penguasaan materi pembelajaran, menggunakan sumber atau media pembalajaran, mengelola interaksi kelas, pelaksanaan tugas, memberikan umpan balik. Sedangkan untuk evaluasi hasil pembelajaran indikatornya berupa, melaksanakan penilaian selama proses pembelajaran, penilaian perilaku siswa dalam pembelajaran, dan hasil pembelajaran.

Berdasarkan pengalaman Program Kegiatan Mengajar (PKM) di Sekolah Menengah Kejuruan Negeri 1 Jakarta pelaksanaan kurikulum 2013, salah satunya dari aspek perencanaan yang dibuat belum mengarahkan siswa untuk lebih aktif dalam proses pembelajaran. Untuk sumber belajar dalam kurikulum 2013 tidak hanya guru, tapi 
banyak sumber dalam mencari materi pelajaran darimana saja dan bagaimana juga guru harus mempersipakan perangkat pembelajarannya sebelum melaksanakan kegiatan belajar mengajar.

Kualitas pendidikan sangat ditentukan oleh kemampuan sekolah dalam mengelola proses pembelajaran yang terjadi di Kelas. Untuk itu peneliti merasa perlu meneliti bagaimana penerapan kurikulum 2013 dalam perencanaan pembelajaran, pelaksanaan pembelajaran, dan evaluasi hasil belajar di SMK Negeri Jakarta Kompetensi Keahlian Teknik Gambar Bangunan, dalam penelitian ini difokuskan pada evaluasi penerapan kurikulum 2013 di SMK Negeri Jakarta pada kegiatan belajar mengajar atau proses pembelajaran. SMK Negeri Komptensi Keahlian Teknik Gambar Bangunan yang sudah menerapkan kurikulum 2013 yang berjumlah 4 sekolah, yaitu SMK Negeri 1, SMK Negeri 26, SMK Negeri 35, SMK Negeri 56 Jakarta.

Dengan sudah diterapkan kurikulum 2013 sebagai suatu sistem selama proses pembelajaran dijalani maka evaluasi akan menjadi hal yang sangat penting, dan peneliti tertarik untuk melakukan penelitian ini dengan judul "Evaluasi Siswa Pada Proses Kegiatan Belajar Mengajar di SMK Negeri Jakarta.

\section{METODOLOGI PENELITIAN}

Metode penelitian yang digunakan adalah metode angket dengan menggunakan instrumen kuisioner untuk menganalisis perencanaan pembelajaran, pelaksanaan pembelajaran dan evaluasi pembelajaran dalam penerapan kurikulum 2013.

Model evaluasi yang peneliti pilih yaitu model stake yang membedakan penelitian menjadi tiga tahap yaitu (1) anteseden (antecedent/context), (2) transaksi (transaction/process), dan (3) keluaran (output-outcomes). Memilih metode ini karena ingin mengetahui pelaksanaan pembelajaran dilihat dari perencanaanya, pelaksanaan dan hasil pembelajaran.

\section{HASIL PENELITIAN DAN PEMBAHASAN}

Data yang diperoleh dalam penelitian ini didapatkan dengan metode pengumpulan data meliputi angket dan dokumentasi. Hasil angket merupakan data primer yang paling penting karena menjadi bagian utama dalam kegiatan analisis data sedangkan dokumentasi merupakan data pendukung yang peneliti gunakan selama melakukan penelitian di Lapangan. Bentuk angket ini sudah disediakan jawaban dan responden menjawab pertanyaan dengan cara memberi tanda ceklis pada jawaban yang sudah disediakan. Angket terdiri dari 36 pertanyaan yang menggambarkan evaluasi proses kegiatan belajar mengajar di SMK Negeri 1, 26, dan 35 Jakarta Kompetensi Keahlian Teknik Gambar Bangunan Mata Pelajaran Gambar Teknik. Lembar angket disusun berdasarkan kisi-kisi angket, dengan item pilihan jawaban Sangat Setuju (SS), Setuju (S), Ragu-ragu (RG), Tidak Setuju (TS), dan Sangat Tidak Setuju (STS) dan responden menjawab sesuai dengan keadaan yang sebenarnya dilakukan di Sekolah.

Lembar angket untuk mengetahui sejauhmana pelaksanan pembelajaran di Sekolah yang diberikan kepada 118 sampel peserta didik kelas $X$ di SMK Negeri 1, SMK Negeri 26, dan SMK Negeri 35 Jakarta, untuk memberikan atas penilaian kinerja guru dalam melaksanakan pembelajaran di Kelas. Alasan dipilihnya peserta didik karena peserta didiklah yang mengetahui dan merasakan 
kinerja guru itu sendiri dalam kegiatan pembelajaran. Pengisian lembar angket ini dilakukan setelah selesai pembelajaran. Pengisian lembar angket kemudian diolah untuk melihat hasil evaluasi proses kegiatan belajar mengajar di SMK Negeri Jakarta dalam penerapan kurikulum 2013 pada Kompetensi Keahlian Teknik Gambar Bangunan.

Dokumentasi digunakan untuk menyajikan hasil data pendukung tentang

Tabel 1 Penilaian Peserta didik tentang Perencanaan Pembelajaran, Pelaksanaan Pembelajaran, dan Evaluasi Pembelajaran

\begin{tabular}{|l|l|l|}
\hline Sub Variabel & Rata-rata & Kategori \\
\hline Perencanaan Pembelajaran & $80,30 \%$ & Sangat Baik \\
\hline Pelaksanaan Pembelajaran & $79,83 \%$ & Baik \\
\hline Evaluasi Pembelajaran & $80,93 \%$ & Sangat Baik \\
\hline Rata-rata & $80,13 \%$ & Sangat Baik \\
\hline
\end{tabular}

Tabel 1 tersebut memperlihatkan bahwa secara umum menurut peserta didik dari tiga sub variabel tersebut tergolong baik dengan perolehan keseluruhan mencapai persentase rata-rata $80,13 \%$ dengan nilai perencanaan pembelajaran $80,93 \%$ dengan kategori sangat baik, nilai pelaksanaan pembelajaran $79,83 \%$ dengan kategori baik, dan nilai evaluasi pembelajaran $80,93 \%$ dengan kategori sangat baik. Data hasil penelitian dari perencanaan pembelajaran, pelaksanaan pembelajaran, dan evaluasi pembelajaran dapat dijelaskan sebagai berikut:

\section{Perencanan Pembelajaran}

Evaluasi terhadap perencanaan pembelajaran yang dilakukan guru dan peserta didik merupakan tahap awal yang menggambarkan kondisi suatu pembelajaran. Evaluasi terhadap perencanaan pembelajaran dalam penelitian ini meliputi beberapa indikator, yaitu: penelitian berupa Rencana Pelaksanaan Pembelajaran (RPP) serta foto dokumentasi Gambaran penilaian peserta didik di SMK Negeri 1, SMK Negeri 26, dan SMK Negeri 35 Jakarta tentang perencanan pembelajaran, pelaksanaan pembelajaran dan evaluasi pembelajaran secara keseluruhan dapat dilihat pada Tabel 1. tentang terlaksananya penelitian ini.

1. Merencanakan pengelolaan kegiatan pembelajaran

2. Merencanakan pengorganisasian bahan pelajaran

3. Merencanakan pengelolaan kelas

4. Merencanakan prestasi belajar peserta didik

Dari empat indikator tersebut peneliti menjabarkan menjadi 9 pertanyaan yang menggambarkan perencanaan pembelajaran dalam penelitian evaluasi proses kegiatan belajar mengajar dalam penerapan kurikum 2013 di SMK Negeri Jakarta pada Kompetensi Keahlian Teknik Gambar Bangunan yang dibagikan kepada 118 responden peserta didik SMK Negeri 1, SMK Negeri 26, dan SMK Negeri 35 Jakarta Mata Pelajaran Gambar Teknik. Untuk lebih jelasnya dapat dilihat pada Tabel 2 . 
Tabel 2 Evaluasi Terhadap Perencanan Pembelajaran

\begin{tabular}{|l|l|l|l|}
\hline No & Indikator Perencanan Pembelajaran & Rata-rata & Kategori \\
\hline 1 & Merencanakan pengelolaan kegiatan pembelajaran & $80,59 \%$ & Sangat Baik \\
\hline 2 & Merencanakan pengorganisasian bahan pelajaran & $83,45 \%$ & Sangat Baik \\
\hline 3 & Merencanakan pengelolaan kelas & $76,10 \%$ & Baik \\
\hline 4 & Merencanakan prestasi belajar peserta didik & $79,49 \%$ & Baik \\
\hline \multicolumn{2}{|l|}{ Rata-rata Perencanaan Pembelajaran } & $80,30 \%$ & Sangat Baik \\
\hline
\end{tabular}

Berdasarkan tabel diatas, diperoleh data secara umum perencanan pembelajaran pada peserta didik kelas X SMK Negeri 1, 26, dan 35 Jakarta pada Kompetensi Keahlian Teknik Gambar Bangunan Mata Pelajaran Gambar Teknik tergolong kategori sangat baik dengan persentase rata-rata $80,30 \%$. Hasil persentase tersebut diperoleh dari skor keseluruhan yang kemudian dirata-rata untuk memperoleh kesimpulan. Tabel evaluasi terhadap perencanan pembelajaran di atas menjelaskan bahwa secara perencanan, pelaksanaan pembelajaran yang dilaksanakan di Sekolah memenuhi kriteria yang baik sesuai dengan prosedur yang ada. Hal ini dapat dilihat dari perencanaan pembelajaran yang tertuang dalam penyusunan Rencana Pelaksanaan Pembelajaran(RPP). Untuk lebih jelasnya tentang
evaluasi terhadap perencanaan pembelajaran, berikut peneliti menjabarkan tabel hasil olah data berdasarkan sub indikator dari perencanaan pembelajaran pada Tabel 3.

Tabel 3 Perencanan Pembelajaran berdasarkan Sub Indikator

\begin{tabular}{|l|l|l|l|}
\hline No & Perencanaan Pembelajaran & Rata-rata & Kategori \\
\hline 1 & $\begin{array}{l}\text { Guru menyampaikan materi yang akan dilaksanakan pada } \\
\text { pertemuan hari ini }\end{array}$ & 79,32 & Baik \\
\hline 2 & $\begin{array}{l}\text { Guru menyampaikan tujuan yang hendak dicapai dalam } \\
\text { setiap pertemuan }\end{array}$ & 81,86 & Sangat Baik \\
\hline 3 & $\begin{array}{l}\text { Guru menyampaikan tentang buku yang akan dipakai pada } \\
\text { proses pembelajaran }\end{array}$ & 79,98 & Baik \\
\hline 4 & $\begin{array}{l}\text { Guru merencanakan dan memanfaatkan berbagai sumber } \\
\text { belajar yang tersedia di Sekolah }\end{array}$ & 84,58 & Sangat Baik \\
\hline 5 & $\begin{array}{l}\text { Guru menggunakan media yang sesuai dalam proses } \\
\text { Kegiatan Belajar Mengajar (KBM) }\end{array}$ & 86,78 & Sangat Baik \\
\hline 6 & $\begin{array}{l}\text { Guru memeriksa kelengkapan peserta didik dalam setiap } \\
\text { pembelajaran }\end{array}$ & 74,24 & Baik \\
\hline 7 & $\begin{array}{l}\text { Guru memeriksa kelengkapan dan kesiapan kelas dalam } \\
\text { pembelajaran }\end{array}$ & 77,97 & Sangat Baik \\
\hline 8 & $\begin{array}{l}\text { Guru memberikan penjelasan tentang teknik evaluasi yang } \\
\text { akan digunakan dalam proses pembelajaran }\end{array}$ & 80,68 & Baik \\
\hline 9 & Guru menjelaskan kapan akan dilaksanakan evaluasi & 78,31 & \\
\hline
\end{tabular}


Hasil perhitungan diatas menunjukkan bahwa indikator-indikator yang menggambarkan perencanan pembelajaran pada peserta didik kelas $X$ menunjukkan kriteria yang sangat baik. Komponen seperti merencanakan pengelolaan kegiatan pembelajaran, perencanan pembelajaran, perencanaan.

\section{Pelaksanaan Pembelajaran}

Pelaksanaan pembelajaran merupakan tahap implementasi yang telah dibuat oleh guru. Evaluasi pelaksaan atau proses pembelajaran ini meliputi beberapa indikator, yaitu:

1. Mengelola ruang, waktu dan fasilitas belajar

2. Menggunakan metode pembelajaran
3. Mengetahui penguasaan materi pembelajaran

4. Menggunakan sumber atau media pembelajaran

5. Mengelola interaksi kelas

6. Pelaksanaan tugas

7. Memberikan umpan balik

Dari tujuh indikator di atas, kemudian dijabarkan ke dalam 21 pertanyaan yang menggambarkan pelaksanan atau proses pembelajaran dalam penelitian evaluasi proses kegiatan belajar mengajar dalam pelaksanaan kurikulum 2013 di SMK Negeri 1, 26, 35 Jakarta Kompetensi Keahlian Teknik Gambar Bangunan pada Mata Pelajaran Gambar Teknik. Untuk lebih jelasnya indikator pelaksanaan pembelajaran dapat dilihat pada Tabel 4.

Tabel 4 Evaluasi terhadap Pelaksanaan Pembelajaran

\begin{tabular}{|l|l|l|l|}
\hline No & Indikator Pelaksanaan Pembelajaran & Rata-rata & Kategori \\
\hline 1 & Mengelola ruang, waktu dan fasilitas belajar & 76,72 & Baik \\
\hline 2 & Menggunakan metode pembelajaran & 77,88 & Baik \\
\hline 3 & Mengetahui penguasaan materi pembelajaran & 79,58 & Baik \\
\hline 4 & Menggunakan sumber atau media pembelajaran & 81,53 & Sangat Baik \\
\hline 5 & Mengelola interaksi kelas & 80,47 & Sangat Baik \\
\hline 6 & Pelaksanaan tugas & 87,54 & Sangat Baik \\
\hline 7 & Memberikan umpan balik & 78,02 & Baik \\
\hline \multicolumn{2}{|l|}{ Rata-rata pelaksaan pembelajaran } & 79,83 & Baik \\
\hline
\end{tabular}

Berdasarkan Tabel di atas bahwa secara umum pelaksanaan pembelajaran pada peserta didik kelas X SMK Negeri di Jakarta pada Kompetensi Keahlian Teknik Gambar Bangunan tergolong baik dengan persentase rata-rata $79,83 \%$. Hasil persentase tersebut diperoleh dari skor keseluruhan yang kemudian dirata-rata untuk memperoleh kesimpulan. Tabel evaluasi terhadap pelaksanaan pembelajaran di atas menjelaskan pelaksanaan bahwa secara umum pembelajaran yang dilaksanakan di Sekolah memenuhi kriteria yang baik, kesiapan guru dalam melaksanakan pembelajaran dengan baik sesuai dengan prosedur yang ada. Bahkan ada tiga indikator yang tergolong sangat baik dalam pelaksanaanya, yaitu Menggunakan sumber atau media pembelajaran, mengelola interaksi kelas dan Pelaksanaan tugas. 
Untuk lebih jelasnya tentang evaluasi terhadap pelaksanan pembelajaran, berikut peneliti menjabarkan Tabel hasil olah data berdasarkan sub indikator dari pelaksanaan pembelajaran pada Tabel 5.

Tabel 5 Pelaksanan Pembelajaran berdasarkan Sub Indikator

\begin{tabular}{|c|c|c|c|}
\hline No & Pelaksaaan Pembelajaran & Rata-rata & Kategori \\
\hline 1 & $\begin{array}{l}\text { Guru menanyakan materi-materi pertemuan sebelumnya } \\
\text { kepada peserta didik diawal pelajaran }\end{array}$ & 77,12 & Baik \\
\hline 2 & $\begin{array}{l}\text { Guru membuka pelajaran dengan mengisi kehadiran } \\
\text { peserta didik }\end{array}$ & 90,17 & Sangat baik \\
\hline 3 & $\begin{array}{l}\text { Guru memberikan tes awal tentang materi yang akan } \\
\text { dipelajari }\end{array}$ & 62,88 & Baik \\
\hline 4 & $\begin{array}{l}\text { Guru menggunakan metode pembelajaran yang bervariasi } \\
\text { sehingga pembelajaran tidak membosankan }\end{array}$ & 74,41 & Baik \\
\hline 5 & $\begin{array}{l}\text { Guru mengupayakan agar proses pembelajaran } \\
\text { berlangsung dalam suasana yang menyenangkan }\end{array}$ & 75,08 & Baik \\
\hline 6 & $\begin{array}{l}\text { Guru menjawab pertanyaan peserta didik dengan jelas } \\
\text { sesuai dengan pertayaan yang ditanyakan oleh peserta } \\
\text { didik }\end{array}$ & 78,64 & Baik \\
\hline 7 & $\begin{array}{l}\text { Guru menggunakan metode demonstrasi untuk } \\
\text { memperjelas penyampaian materi pembelajaran }\end{array}$ & 83,39 & Sangat baik \\
\hline 8 & $\begin{array}{l}\text { Guru dalam menyampaikan materi menggunakan bahasa } \\
\text { lisan dan tulisan secara jelas dan mudah dimengerti }\end{array}$ & 76,78 & Baik \\
\hline 9 & $\begin{array}{l}\text { Guru menyampaikan materi dengan menarik dan mudah } \\
\text { dipahami oleh peserta didik }\end{array}$ & 82,37 & Sangat baik \\
\hline 10 & $\begin{array}{l}\text { Guru menggunakan media yang sesuai dalam setiap } \\
\text { proses pembelajaran }\end{array}$ & 79,49 & Baik \\
\hline 11 & $\begin{array}{l}\text { Guru dalam mengajar menggunakan contoh yang ada di } \\
\text { sekitar Sekolah }\end{array}$ & 82,88 & Sangat baik \\
\hline 12 & $\begin{array}{l}\text { Guru menggunakan salah satu sumber buku sebagai } \\
\text { acuan dalam pembelajaran }\end{array}$ & 82,20 & Sangat baik \\
\hline 13 & $\begin{array}{l}\text { Guru menunjukkan perilaku yang penuh kesabaran dan } \\
\text { tidak marah ketika peserta didik mengalami kesalahan } \\
\text { dalam proses pembelajaran }\end{array}$ & 78,14 & Baik \\
\hline 14 & $\begin{array}{l}\text { Guru berkeliling mendekati peserta didik untuk memantau } \\
\text { perkembangan peserta didik dalam belajar }\end{array}$ & 80,00 & Sangat Baik \\
\hline 15 & $\begin{array}{l}\text { Guru memperlakukan peserta didik secara adil tanpa } \\
\text { memandang suku, agama, ras, dan status sosial }\end{array}$ & 84,41 & Sangat baik \\
\hline 16 & $\begin{array}{l}\text { Guru menberikan kesempatan kepada peserta didik untuk } \\
\text { bertanya bagi yang belum jelas terhadap materi yang } \\
\text { disampaikan }\end{array}$ & 79,32 & Baik \\
\hline 17 & $\begin{array}{l}\text { Guru memberikan tes tertulis di akhir pembelajaran sesuai } \\
\text { dengan materi yang diajarkan }\end{array}$ & 85,59 & Sangat baik \\
\hline 18 & Guru memberikan tugas sesuai dengan kompetensi dasar & 89,49 & Sangat baik \\
\hline
\end{tabular}




\begin{tabular}{|c|c|c|c|}
\hline No & Pelaksaaan Pembelajaran & Rata-rata & Kategori \\
\hline & yang diajarkan & & \\
\hline 19 & $\begin{array}{l}\text { Guru mengembalikan pekerjaan peserta didik yang telah } \\
\text { dikoreksi }\end{array}$ & 67,80 & Baik \\
\hline 20 & $\begin{array}{l}\text { Guru mengajak peserta didik untuk membuat rangkuman } \\
\text { atas kesimpulan materi yang telah dipelajari }\end{array}$ & 80,85 & Baik \\
\hline 21 & $\begin{array}{l}\text { Guru melakukan penilaian terhadap kemampuan peserta } \\
\text { didik dalam proses pembelajaran }\end{array}$ & 85,42 & Sangat baik \\
\hline \multicolumn{2}{|c|}{ Rata-rata Pelaksanaan Pembelajaran } & 79,83 & Baik \\
\hline
\end{tabular}

Hasil perhitungan dapat disimpulkan bahwa pelaksanaan pembelajaran pada peserta didik kelas $X$ di SMK Negeri 1, 26, 35 Jakarta Kompetensi Keahlian Teknik Gambar Bangunan pada Mata Pelajaran Gambar Teknik berjalan dengan baik, bahkan ada bebera sub indikator yang dengan kategori sangat baik, data tersebut diperoleh dari hasil penelitian di Sekolah.

\section{Evaluasi Pembelajaran}

Evaluasi merupakan bagian yang penting dalam setiap kegiatan pembelajaran. Baik tidaknya pembelajaran dapat diketahui dari hasil evaluasi yang dilakukan. Dalam pelaksanaan pembelajaran, evaluasi tidak hanya dilakukan diakhir pembelajaran, namun dapat pula dilakukan pada saat pembelajaran atau proses pembelajaran atau yang disebut

\begin{tabular}{|l|l|l|l|}
\hline No & Indikator Hasil Pembelajaran & Rata-rata & Kategori \\
\hline 1 & Melaksanakan penilaian selama proses pembelajaran & 76,78 & Baik \\
\hline 2 & Penilaian perilaku peserta didik dalam pembelajaran & 83,90 & Sangat Baik \\
\hline 3 & Hasil belajar peserta didik & 82,12 & Sangat Baik \\
\hline \multicolumn{2}{|l|}{ Rata-rata evaluasi hasil belajar } & 80,90 & Sangat Baik \\
\hline
\end{tabular}

\section{Berdasarkan Tabel 4.6 bahwa} secara umum penilaian hasil belajar peserta didik kelas X SMK Negeri Jakarta tergolong sangat baik dengan persentase rata-rata $80,90 \%$. Hasil persentase tersebut diperoleh skor keseluruhan kemudian dirata-ratakan untuk mendapatkan kesimpulan. Tabel dengan evaluasi proses. Evaluasi terhadap penilaian pembelajaran dalam penelitian ini meliputi beberapa indikator, yaitu:

1. Melaksanakan penilaian selama proses pembelajaran

2. Penilaian perilaku peserta didik dalam pembelajaran

3. Hasil belajar peserta didik

Dari tiga indikator, kemudian dijabarkan kedalam 6 pertanyaan yang menggambarkan penilaian atau hasil pelaksanaan pembelajaran. Hasil olah data evaluasi terhadap penilaian atau hasil diungkapkan menggunakan angket. Untuk lebih jelasnya dapat dilihat pada Tabel 6 . 
keterampilan peserta didik semata, tetapi juga menilai sikap dan perilaku peserta didik dalam setiap pembelajaran, kemampuan guru dalam melakukan penilaian terhadap kemampuan peserta didik dalam proses pembalajaran tergolong baik. Tugas-tugas yang diberikan juga dinilai dengan maksimal untuk melatih kedisiplinan, sikap dan keterampilan peserta didik, maka penilaian bagi peserta didik aktif bertanya ataupun menjawab pertanyaan dalam proses pembelajaran juga dilakukan. Untuk lebih jelasnya dapat dilihat pada Tabel 7 .

Tabel 7 Evaluasi Pembelajaran berdasarkan Sub Indikator

\begin{tabular}{|l|l|l|l|}
\hline No & Evaluasi Pembelajaran & Rata-rata & Kategori \\
\hline 1 & $\begin{array}{l}\text { Guru memberikan saran atau masukan terhadap tugas- } \\
\text { tugas yang telah dikerjakan peserta didik }\end{array}$ & 80,39 & Sangat Baik \\
\hline 2 & $\begin{array}{l}\text { Guru melakukan penilaian tentang tugas-tugas yang } \\
\text { diberikan kepada peserta didik }\end{array}$ & 70,17 & Baik \\
\hline 3 & $\begin{array}{l}\text { Guru menilai peserta didik yang aktif bertanya ataupun } \\
\text { menjawab dalam proses pembelajaran }\end{array}$ & 82,03 & Sangat Baik \\
\hline 4 & $\begin{array}{l}\text { Guru menyampaikan hasil evaluasi pembelajaran baik } \\
\text { ulangan harian, tugas, ujian tengah semester, ujian } \\
\text { akhir semester secara transparan }\end{array}$ & 85,76 & Sangat Baik \\
\hline 5 & $\begin{array}{l}\text { Guru membahas hasil pekerjaan peserta didik atau } \\
\text { hasil tes kepada peserta didik didepan kelas }\end{array}$ & 82,37 & Sangat baik \\
\hline 6 & $\begin{array}{l}\text { Guru mengadakan remedial bagi peserta didik yang } \\
\text { belum tuntas pada setiap kompetensi dasar }\end{array}$ & 81,86 & Sangat Baik \\
\hline \multicolumn{2}{|l|}{ Rata-rata evaluasi pembelajaran } & 80,93 & \\
\hline
\end{tabular}

Terlihat pada Tabel 4.7 bahwa guru menunjukkan penilaian diakhir pelajaran untuk mengetahui sejauh mana penguasaan peserta didik terhadap materi yang telah diajarkan. Tidak hanya itu, guru juga terkadang menyampaikan hasil evaluasi secara transparan. Tindakan ini untuk memotivasi peserta didik agar selalu mempertahankan proses belajar bagi yang sudah kompoten dan meningkatkan kualitas belajarnya bagi yang belum kompoten menerima pelajaran. Remedial juga dilakukan terutama bagi yang belum tuntas. Hasil perhitungan diatas dapat disimpulkan bahwa penilaian pembelajaran berjalan dengan sangat baik.

\section{KESIMPULAN}

1. Dengan ini evaluasi terhadap perencanaan pembelajaran dikategorikan sangat baik dengan ratarata $80,30 \%$.

2. Pelaksanaan proses pembelajaran dikategorikan baik dengan rata-rata $79,83 \%$.

3. Evaluasi hasil pembelajaran dikategorikan Sangat baik $(80,93 \%)$

4. Secara keseluruhan evaluasi terhadap proses kegiatan belajar mengajar di SMK Negeri Jakarta khususnya SMK Negeri 1, 26, dan 35 Jakart Kompetensi Keahlian Teknik Gambar Bangunan pada Mata Pelajaran Gambar Teknik dilihat dari perencanaan pembalajaran, pelaksanaan pembelajaran dan evaluasi 
hasil pembelajaran tergolong Sangat baik dengan rata-rata $80,13 \%$.

\section{DAFTAR PUSTAKA}

Ahmad, Zainal Arifin. 2012. Perencanaan Pembelajaran: dari desain Sampai Implemenetasi. Yogyakarta: PT Pustaka Insan Madani

Arikunto, Suharsimi, 2009. Dasar-dasar Evaluasi Pendidikan. Jakarta: Bumi Aksara.

Arikunto, Suharsimi \& Cepi Safruddin Abdul Jabar. 2009. Evaluasi Program Pendidikan Pedoman Teoritis Bagi Mahasiswa dan Praktisi Pendidikan. Jakarta: Bumi Aksara.

Haryati, Mimin. 2007. Model dan Teknik Penilaian Pada Tingkat Satuan Pendidikan Cetakan Ke-1. Jakarta: Gaung Persada Press.

Humasah, \& Setianingrum, Yanur. 2013. Desain Pembelajaran Berbasis Pencapain Kompetensi Panduan Memahami Pembelajaran Untuk mendukung Implimentasi Kurikulum 2013. Jakarta: PT Pustaka Karya.

Majid, Abdul. 2011. Perencanaan Pembelajaran Mengembangkan Standar Kompetensi Guru. Bandung: PT Remaja Rosdakarya Offset.

Margono. S. 2010. Metodologi Penelitian Pendidikan. Jakarta: PT. Rhineka Cipta.

Mulyasa, E. 2013. Pengembangan dan Implementasi Kurikulum 2013. Bandung: PT Rosda Karya.

Muzamiroh, Mida Latifatul. 2013. Kupas Tuntas Kurikulum 2013 Kelebihan dan Kekurangan Kurikulum 2013. Kata Pena.

Purwanto. 2009. Evaluasi Hasil Belajar. Yogyakarta: Pustaka Belajar.

Purwanto. 2007. Metodologi Penelitian Kuantitatif Untuk Psikologi dan Pendidikan. Yogyakarta: Pustaka Pelajar.

Republik Indonesia. 2003. Undang-undang No. 20 Tahun 2003 Tentang Sistem Pendidikan Nasional. Jakarta.

Republik Indonesia. 2013. Peraturan Menteri Pendidikan dan Kebudayaan Nomor 65 Tentang Standar Proses Pendidikan Dasar dan Menengah. Jakarta.

Salahudin, Anas. 2011. Filsafat Pendidikan. Bandung: CV Pustaka.

Sanjaya, Wina. 2009. Kurikulum dan Pengembangan Teori dan Praktik Pengembangan Kurikulum Tingkat Satuan Pendidikan (KTSP). Jakarta: Kencana.

Sudjana, Nana. 2009. Penilaian Hasil Proses Belajar Mengajar. Bandung: PT. Remaja Rosdakarya.

Sugiono, 2010. Metode Penelitian Kuantitatif, Kualitatif dan $R$ \& $D$. Bandung: $C V$. Alfabeta.

Sugiono, 2011. Metode Penelitian Kuantitatif Kualitatif dan $R$ \& $D$. Bandung: Alfabeta.

Widoyoko, Eko Putro, 2013. Evaluasi Program Pembelajaran Panduan Praktis Bagi Pendidik Dan Calon Pendidik. Yogyakarta: Pustaka Pelajar. 